A influência litológica nas taxas de denudação geoquímica do médio Espinhaço Meridional - MG Éric Andrade Rezende, Marina Ribeiro Leão, André Augusto Rodrigues Salgado, Carmélia Kerolly Ramos de Oliveira, Hermínio Arias Nalini Júnior

\title{
A INFLUÊNCIA LITOLÓGICA NAS TAXAS DE DENUDAÇÃO GEOQUÍMICA DO MÉDIO ESPINHAÇO MERIDIONAL - MG
}

\section{Lithological influence on rates of geochemical denudation in the middle Espinhaço Meridional - MG}

\author{
Éric Andrade Rezende \\ Graduando em Geografia da Universidade Federal de Minas Gerais \\ Belo Horizonte/MG - Brasil \\ ear.88@hotmail.com \\ Marina Ribeiro Leão \\ Mestranda em Geografia da Universidade Federal de Minas Gerais \\ Belo Horizonte/MG - Brasil \\ marina.rleao@gmail.com
}

André Augusto Rodrigues Salgado Professor adjunto do Departamento de Geografia do IGC/UFMG Belo Horizonte/MG - Brasil geosalgado@yahoo.com.br

Carmélia Kerolly Ramos de Oliveira Graduanda em Geografia da Universidade Federal de Minas Gerais Belo Horizonte/MG - Brasil carmeliageo2008@gmail.com

Hermínio Arias Nalini Júnior Professor Associado do Departamento de Geologia - Escola de Minas da UFOP Ouro Preto/MG - Brasil nalini@degeo.ufop.br

Artigo recebido para publicação em 10/07/2010 e aceito para publicação em 09/11/2010

RESUMO: O presente trabalho visa investigar a influência da litologia nas atuais taxas de denudação geoquímica na média Serra do Espinhaço Meridional. As taxas de denudação correspondem ao volume de material proveniente da alteração das ro chas retirado de uma determinada área em um dado período de tempo (Souch, 2004). Estas taxas são intensamente controladas pelo substrato geológico, notadamente em bacias hidrográficas de menor extensão. O método adotado baseia-se na coleta de amostras das águas superficiais de dezesseis sub-bacias hidrográficas - que apresentam baixa interferência antrópica e estão sobre substrato geológico predominantemente quartzítico - e na medição da vazão dos canais amostrados. Análises químicas de águas superficiais, coletadas nos períodos úmido e seco do ano, foram utilizadas no cálculo da taxa de denudação geoquímica, que, de modo geral, apresentou-se baixa devido a alta resistência dos quartzitos - litologia predominante. Os resultados demonstraram que, apesar da relativa homogeneidade litológica, a área apresenta uma denudação geoquímica diferencial, onde: (i) bacias que drenam rochas carbonáticas possuem taxas mais elevadas de denudação, confirmando a alta solubilidade desse material, (ii) bacias que drenam unidades quartzíticas apresentam taxas baixas de denudação, principalmente aquelas sobre as formações Galho do Miguel e Sopa-Brumadinho. 
Palavras-chave: Denudação geoquímica. Serra do Espinhaço Meridional. Litologia.

ABSTRACT: This paper investigates the relationship between lithology and geochemical denudation rates in the middle Serra do Espinhaço Meridional. Denudation rates represent the volume of material from the alteration of rocks taken from a specified area at a known time period (Souch, 2004). These rates are strongly controlled by geological substrate, especially in less extensive watersheds. The method adopted is based on sampling of surface waters of sixteen sub-basins - that have low human interference and drain predominantly quartzite - and measuring the sampled channels flow. Chemical analysis of surface water collected in the humid and dry periods of the year were used to calculate geochemical denudation, which generally showed low in spite of the predominant rock resistance to weathering and denudational processes. The results showed that despite the relatively homogeneous lithology, the area does not hide the finding of a differential geochemical denudation, where: (i) basins that drain carbonate rocks have higher denudation rates, confirming the high solubility of this material, (ii) basins draining quartzite units show low denudation rates, especially the ones over the formations of Galho do Miguel and SopaBrumadinho.

Keywords: Chemical denudation. Serra do Espinhaço Meridional, Lithology.

\section{INTRODUÇÃO}

Entre os principais processos da dinâmica das vertentes está a dissolução e remoção de solutos do solo e da rocha subjacente pelas águas superficiais e de infiltração (MELO et al., 2005). Esse processo é o principal fornecedor de materiais que irão compor a carga dissolvida dos cursos fluviais, já que esta é formada, em sua maioria, pelos constituintes intemperizados das rochas. Deste modo, a composição da carga dissolvida reflete a distribuição espacial dos diversos tipos de rocha e, embora não seja visível, representa parcela importante da denudação continental (CHRISTOFOLETTI, 1981; LEEDER, 1991).

As taxas de denudação correspondem ao volume de material proveniente da alteração das rochas retirado de uma determinada área em um dado período de tempo (SOUCH, 2004). De acordo com Summerfield (1991) em escala local os principais controladores do fornecimento de sedimentos e carga dissolvida são a litologia e fatores específicos de erodibilidade, enquanto em escala global as taxas de denudação são determinadas fundamentalmente pelo relevo e tectônica, e em menor extensão pelo clima. Portanto, as taxas denudacionais são intensamente controladas pelo substrato geológico, notadamente em bacias hidrográficas de menor extensão.
Na Serra do Espinhaço Meridional, o primeiro trabalho que investigou a erosão diferencial com base na quantificação dos processos denudacionais geoquímicos foi o de Salgado e Valadão (2003). Esses autores restringiram seu estudo à Depressão de Gouveia e seu entorno e verificaram a existência de dois comportamentos distintos na área investigada: (i) elevadas taxas de denudação geoquímica nas áreas topograficamente deprimidas que ocupam o piso da Depressão de Gouveia, modelada nas rochas granitóides, gnáissicas e migmatíticas do Complexo Gouveia e; (ii) baixas taxas de denudação geoquímica nos planaltos que circundam essa depressão, modelados, sobretudo, nas unidades quartzíticas do Supergrupo Espinhaço. Resultados semelhantes foram encontrados por Salgado et al. (2004) no Quadrilátero Ferrífero, que demonstraram quantitativamente a existência de uma denudação geoquímica diferencial, em que: quartzitos e itabiritos constituem as rochas mais resistentes; xistos, filitos, granitos e gnaisses as de resistência mediana; e mármores e dolomitos as de menor resistência.

Nesse contexto, o presente trabalho tem como objetivo compreender a influência litológica em relação às atuais taxas de denudação geoquímica de sub-bacias hidrográficas da média Serra do Espinhaço Meridional. Essa região é ainda pouco estudada do 
ponto de vista geomorfológico, assim a compreensão da relação entre o substrato geológico e a perda geoquímica das bacias certamente fornecerá um importante subsídio para o entendimento da evolução do modelado regional.

\section{CARACTERIZAÇÃO DA ÁREA DE ESTUDO}

A Serra do Espinhaço representa uma faixa paleo-orogênica que limita a bacia hidrográfica do rio São Francisco, localizada sobre o cráton homônimo, com as bacias que drenam diretamente para o oceano Atlântico. No Estado de Minas Gerais constitui um conjunto de terras elevadas com uma relativa homogeneidade litológica. A porção meridional da Serra do Espinhaço apresenta uma maior amplitude transversal e sua morfologia é caracterizada por planaltos elevados interceptados por escarpas quartzíticas (GROSSI-SAD et al., 1997). $\mathrm{O}$ presente trabalho investiga a área aqui denominada como Média Serra do Espinhaço Meridional, localizada ao sul do Planalto de Diamantina e ao norte da Serra do Cipó (Figura 1).
A Serra do Espinhaço Meridional (SdEM) é edificada essencialmente por litologias do Supergrupo Espinhaço (Figura 2), composto, principalmente, por quartzitos e, subordinadamente, por metassiltitos, metaconglomerados, filitos e metavulcanitos de caráter básico e ácido (ALMEIDA-ABREU, 1995). A predominância de quartzitos condiciona uma cobertura mais resistente, densamente falhada e fraturada, cujo modelado configura a existência de escarpas, linhas de cimeira e grandes desníveis topográficos, organizados de acordo com as direções tectônicas e estruturais (SAADI, 1995; VALADÃO, 1998). Nas regiões deprimidas, entre Gouveia e Conceição do Mato Dentro, aflora o Complexo Basal composto por rochas granitóides, metassedimentares e metavulcânicas onde predominam colinas policonvexas mais ou menos suavizadas (SAADI, 1995). Contornando essa serra e sobrepondo localmente suas faixas limítrofes, afloram unidades dos grupos Macaúbas - predominantemente quartzitos - e Bambuí - predominantemente rochas carbonáticas.

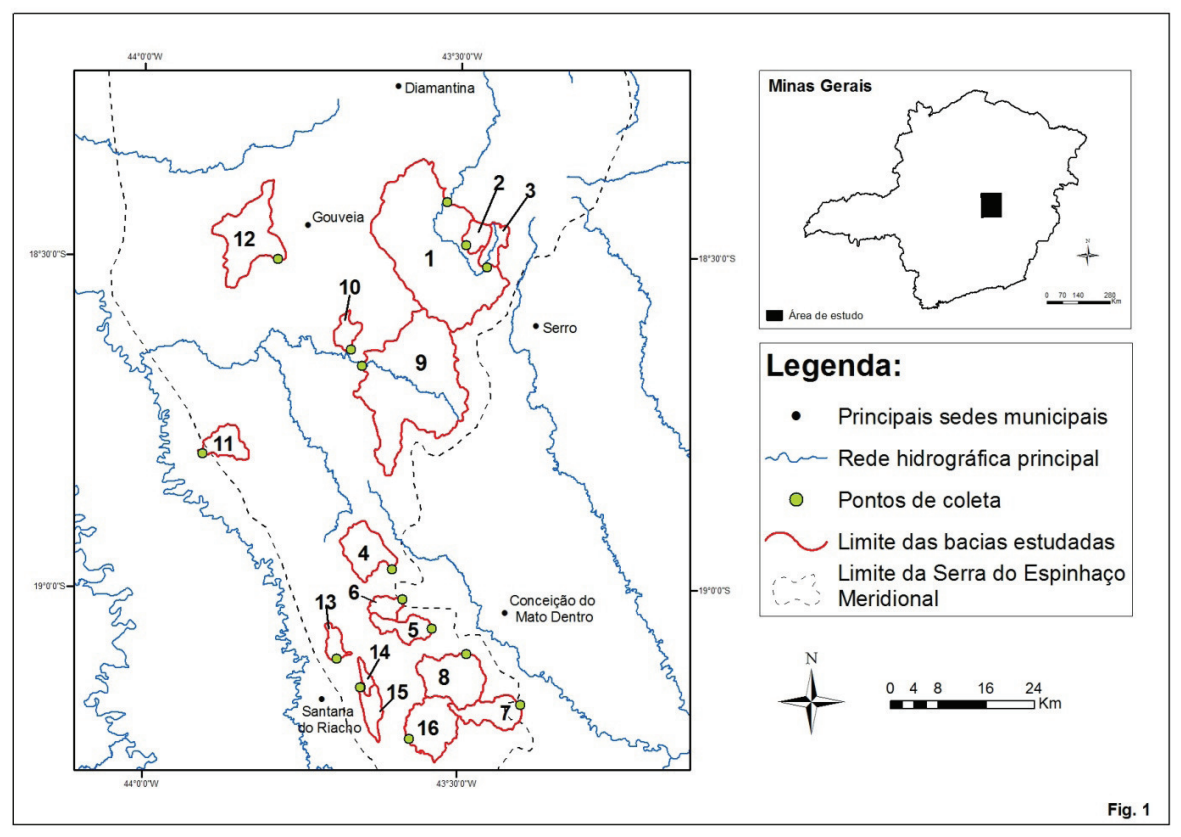

Figura 1: Localização das bacias estudadas na Serra do Espinhaço

1: Alto Rio Jequitinhonha; 2: Córrego Fundo (Moinho); 3: Alto Rio Jequitinhonha (nascente); 4: Alto Rio Parauninha; 5: Rio Preto; 6: Córrego Teodoro (Mata Cavalos); 7: Ribeirão Mata Cavalos; 8: Rio Cuba (Três Barras); 9: Alto Rio Paraúna; 10: Córrego Taquara; 11: Córrego

dos Fechados; 12: Ribeirão da Areia; 13: Córrego Lapinha; 14: Córrego Lajeado; 15: Córrego Mata-Capim; 16: Ribeirão Capivara 


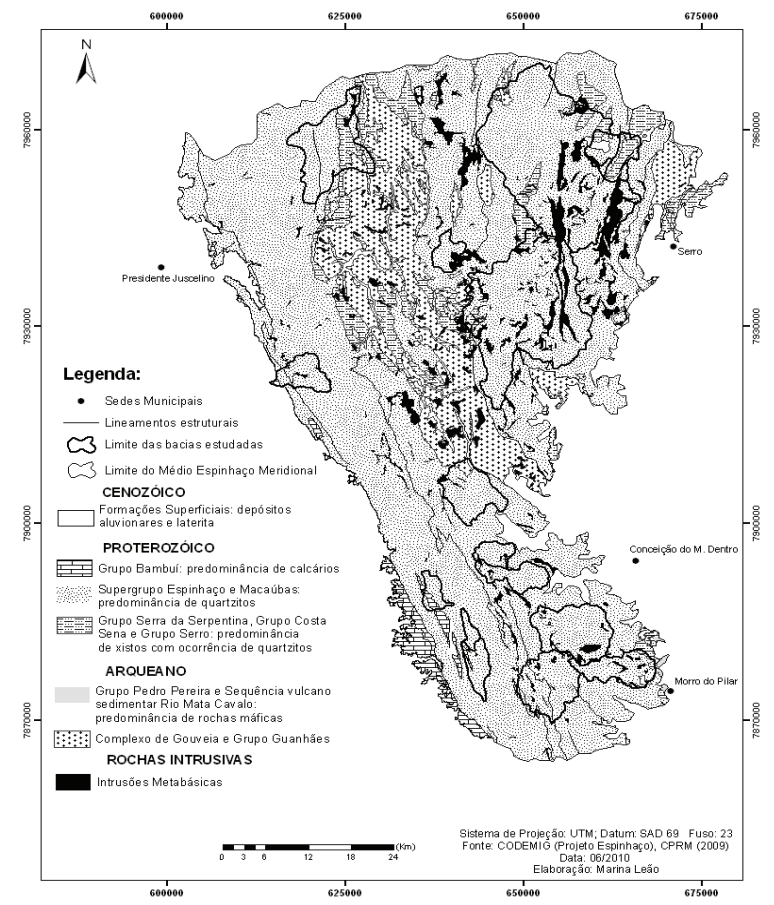

Figura 2: Mapa litológico simplificado da área de estudo.

As faixas de dobramentos que circundam o Cráton do São Francisco promoveram o transporte de matéria no sentido do cráton e, conferiram a ele esforços compressionais (VALADÃO, 1998). O padrão estrutural demonstra a intensa deformação das rochas, sendo o modelado marcado pela orientação estrutural de suas feições morfológicas. Empurrões e dobras com vergência para oeste configuram a escarpa ocidental como uma feição morfotectônica típica de front de cavagalmento, enquanto o escarpamento que constitui a borda leste é descontínuo e freqüentemente composto por dois ou mais degraus $\mathrm{e}$ bruscas mudanças de direção (SAADI, 1995).

O clima da região é mesotérmico, $\mathrm{Cwb}$ na classificação de Koppen, caracterizado por verões brandos e úmidos (outubro a abril), invernos mais frescos e secos (junho a agosto) e curtas transições nos meses de maio e setembro. A precipitação e a temperatura médias anuais variam de 1250 a $1550 \mathrm{~mm}$ e $18^{\circ}$ a $19^{\circ} \mathrm{C}$, respectivamente (NEVES et al., 2005). Contudo a topografia compartimenta diferentes domínios climáticos: (i) as porções altimétricamente mais elevadas apresentam temperaturas sensivelmente mais baixas que as bordas da SdEM; (ii) a porção oeste apresenta estação seca muito mais pro- nunciada do que a leste.

Os aspectos pedológicos da SdEM demonstramse fortemente associados às formas de relevo e ao substrato geológico, desta forma, existe uma relação entre as superfícies geomórficas e as classes de solos presentes na região (DINIZ et al., 2005). Na SdEM predomina o Neossolo Litólico que é desenvolvido associado as rochas quartzíticas. Nas regiões de bordas da SdEM e em seus interior, principalmente em área moldada sobre o embasamento granítico-gnaíssico, xistos, filitos e intrusão rochas metabásicas, rochas mais susceptíveis ao intemperismo, há a ocorrência de solos mais desenvolvidos: os Latossolos e Cambissolos (SILVA, 2005).

A cobertura vegetal original da área de estudo é condicionada por estas características climáticas e pedo-geológicas. As áreas mais elevadas - geralmente moldadas sobre os quartzitos - apresentam vegetação de campo rupestre e subsidiariamente, campo limpo. As porções topograficamente menos elevadas apresentam duas regiões fitoecológicas: (i) a vertente leste é marcada pela floresta semi-decidual; (ii) a vertente oeste é coberta por savana (cerrado), que apresenta distintas formações vegetais. 


\section{MATERIAL E MÉTODOS}

O método adotado baseia-se na coleta de amostras das águas superficiais de dezesseis sub-bacias hidrográficas que foram selecionadas na área de estudo (Figuras 1 e 2). A seleção das bacias investigadas procurou amostrar bacias que: (i) apresentam baixa interferência antrópica; (ii) estão sobre substrato geológico predominantemente quartzítico, embora outras litologias, como xistos, filitos, rochas metabásicas e rochas carbonaticas estejam presentes em porcentagens inferiores e, (iii) possuam ampla distribuição espacial na média Serra do Espinhaço Meridional.

As amostras foram coletadas em dois períodos distintos do ano de modo a representar cada uma das estações climáticas: fevereiro de 2009 (período úmido) e julho de 2009 (período seco). A opção por duas campanhas de amostragem se deve as características do clima regional. Fevereiro corresponde ao início do fim do período úmido. Logo, os cursos fluviais já estão cheios e raros são os eventos pluviométricos que alteram significativamente sua vazão. Já em julho, em plena seca, os cursos fluviais apresentam uma vazão média para este período do ano e não existem riscos de chuvas que possam alterar estas vazões. Por fim, fevereiro e julho, representam os opostos do clima regional e com isso, suas vazões quando somadas e divididas, representam uma média anual aproximada (Salgado, 2002).

Para cada ponto selecionado foi coletada uma amostra em cada período do ano. As coletas foram feitas no centro dos canais fluviais com o auxilio de seringas de $25 \mathrm{ml}$. As águas coletadas foram filtradas com filtros descartáveis de 0,45 micrometros e acondicionadas em frascos virgens de $100 \mathrm{ml}$ aos quais, para melhor conservação, acrescentaram-se duas gotas de ácido nítrico (HNO3) puro. Os sólidos totais dissolvidos (TDS) foram mensurados via espectrometria de emissão atômica por plasma (ICP-OES Spectro Cirus CCD), no LGqA - Laboratório de Geoquímica Ambiental do Departamento de Geologia da Universidade Federal de Ouro Preto.

Em cada campanha de campo foram medidas a largura $(\mathrm{m})$, a profundidade média $(\mathrm{m})$ e a velocidade média do fluxo de água $(\mathrm{m} / \mathrm{s})$ de cada curso fluvial no mesmo local de coleta das amostras. Esses dados foram usados para o cálculo da vazão semestral $\left(\mathrm{m}^{3} /\right.$ semestre). As bacias foram delimitadas e tiveram suas áreas calculadas $\left(\mathrm{km}^{2}\right)$ com o uso do software Arcgis 9.2. Posteriormente os sólidos totais dissolvidos ( $\mathrm{g} /$ $\mathrm{m}^{3}$ ) foram correlacionados à vazão $\left(\mathrm{m}^{3} /\right.$ semestre $) \mathrm{e}$ à área de cada bacia $\left(\mathrm{km}^{2}\right)$ para a obtenção das taxas de denudação geoquímica semestrais (toneladas $/ \mathrm{Km}^{2} /$ semestre). Com a soma das duas taxas semestrais obteve-se a denudação geoquímica anual (toneladas/ $\mathrm{km}^{2} / \mathrm{ano}$ ) de cada uma das bacias.

Neste ponto, vale ressaltar que este cálculo de denudação geoquímica não corresponde a um cálculo exato, mas sim a uma aproximação. No entanto, esta aproximação é válida, pois todas as amostras foram coletadas, em cada campanha, num intervalo de tempo de no máximo três dias, sendo que, mesmo na campanha durante o período úmido do ano (fevereiro de 2009) não ocorreram eventos pluviométricos. Sendo assim, a comparação entre as taxas obtidas nas diferentes bacias pode ser realizada. E é nesta comparação que se baseiam as considerações deste artigo.

Foi realizado então, o cálculo da participação $\left(\mathrm{Km}^{2} \mathrm{e} \%\right)$ de cada unidade litoestratigráfica em relação à área total das bacias. A base cartográfica digital utilizada nesse processo corresponde ao mapeamento geológico na escala de 1:100.000 realizado pelo Projeto Espinhaço (Grossi-Sad et al., 1997). De modo a facilitar as análises, as unidades foram agrupadas segundo o litotipo predominante de cada uma delas da seguinte maneira: (i) Predomínio de quartzitos; (ii) Predomínio de metapelitos; (iii) Granitos e Gnaisses; (iv) Rochas Metabásicas; (v) Rochas Carbonáticas; (vi) Coberturas terciárias/ quaternárias (Quadro 1).

De posse desses dados, foi possível realizar uma análise comparativa entre a composição do substrato geológico de cada uma das bacias e suas respectivas taxas denudacionais.

\section{RESULTADOS E DISCUSSÃO}

É possível observar certa regularidade na intensidade com que cada unidade litológica condiciona maiores ou menores taxas de denudação geoquímica nas bacias selecionadas (Tabela. 2). As poucas bacias que não se enquadram totalmen- 
A influência litológica nas taxas de denudação geoquímica do médio Espinhaço Meridional - MG

Éric Andrade Rezende, Marina Ribeiro Leão, André Augusto Rodrigues Salgado, Carmélia Kerolly Ramos de Oliveira, Hermínio Arias Nalini Júnior

\begin{tabular}{|c|c|}
\hline Litotipo predominante & Unidades litológicas* \\
\hline Predomínio de quartzitos & $\begin{array}{c}\text { Grupo Macaúbas; Formações Galho do Miguel, Sopa- } \\
\text { Brumadinho, São João da Chapada e Córrego dos Borges; Unidades } \\
\text { Itambé do Mato Dentro, Rio Preto, Rio Preto (nível fosfatado) e } \\
\text { Serra do Lobo; Membro Campo Sampaio. }\end{array}$ \\
\hline Predomínio de metapelitos & $\begin{array}{c}\text { Grupos Costa Sena e Serra da Serpentina (unidade xistosa); } \\
\text { Formações Santa Rita, Córrego da Bandeira e Serra de Santa Helena. }\end{array}$ \\
\hline Granitos e Gnaisses & Complexo Gouveia \\
\hline Rochas Metabásicas & Soleiras e diques máficos e Suíte Pedro Lessa \\
\hline Rochas Carbonáticas & Formação Sete Lagoas \\
\hline Coberturas terciárias/quaternárias & Coberturas elúvio-coluvionares \\
\hline
\end{tabular}

Quadro 1: Agrupamento das unidades litológicas segundo o litotipo predominante.*Agrupamento realizado com base nas unidades de mapeamento definidas pelo Projeto Espinhaço (GROSSI-SAD et al., 1997).

te nessa regularidade, como os córregos Teodoro, Mata-Capim e Lajeado, possuem vazão específica $\left(\mathrm{m}^{3} / \mathrm{s} / \mathrm{Km}^{2}\right)$ bastante discrepante da média geral (Tabelas 2 e 3 ).

As rochas carbonáticas, representadas na área pela Formação Sete Lagoas, constituem a litologia que mais claramente condiciona elevadas taxas denudacionais. As bacias dos Córregos Lapinha e Mata-Capim são as únicas, entre as estudadas, a possuírem como substrato geológico alguma porcentagem desta formação, composta predominantemente por calcários e mármores (OLIVEIRA et al., 1997). São justamente essas duas bacias que apresentam as maiores taxas de denudação geoquímica (ton $/ \mathrm{km}^{2} / \mathrm{ano}$ ): 18,94 e 25,65 respectivamente, comprovando assim, a elevada solubilidade dessas rochas.

As unidades predominantemente quartzíticas abrangem a maior parte da área de estudo e, de modo geral, apresentam alta resistência. No entanto, é possível observar comportamentos diferenciados entre as diversas unidades (Tabela 1) pertencentes a esse agrupamento anteriormente definido (Quadro 1). As bacias onde afloram com abundância as unidades Itambé do Mato Dentro, Rio Preto e Rio Preto (nível fosfatado) têm tendência a apresentarem taxas mais altas, como no caso das bacias do Ribeirão Mata Cavalos e do Rio Cuba (Três Barras) (Tabela 1). Essa correlação é mais claramente explicada no caso da Unidade Rio
Preto que possui em meio aos quartzitos finos, níveis carbonáticos e fosfatados (GROSSI-SAD et al., 1997), sendo esses mais facilmente lixiviados. Já no caso da Unidade Itambé do Mato Dentro, a explicação pode estar na existência de níveis pelíticos que localmente podem ser abundantes (GROSSI-SAD et al., 1997).

As formações Galho do Miguel e Sopa-Brumadinho são as de maior representatividade espacial na Serra do Espinhaço Meridional e, deste modo são também as grandes responsáveis pelo predomínio de taxas denudacionais bastante baixas nas bacias estudadas. De modo a permitir uma comparação, é válido citar que as estimativas de denudação química dos maiores rios situados em zonas de relevo moderado e clima temperado ou tropical ficam entre 25,00 e $60,00 \mathrm{ton} / \mathrm{km}^{2} /$ ano, enquanto em zonas montanhosas de elevada precipitação podem chegar até 350,00 ton $/ \mathrm{km}^{2} /$ ano (SOUCH, 2004). As bacias do Rio Jequitinhonha e do Ribeirão da Areia são bons exemplos da elevada resistência imposta por essas duas formações quartzíticas, Sopa-Brumadinho e Galho do Miguel, já que apresentam taxas de 1,93 e $2,63 \mathrm{ton} / \mathrm{km}^{2} /$ ano respectivamente.

A análise da influência das demais unidades litológicas fica bastante prejudicada pela sua pequena participação na área das bacias estudadas. A baixa representatividade dessas unidades faz com que seu papel no controle das taxas de denudação geoquímica fique bastante reduzido frente ao amplo 


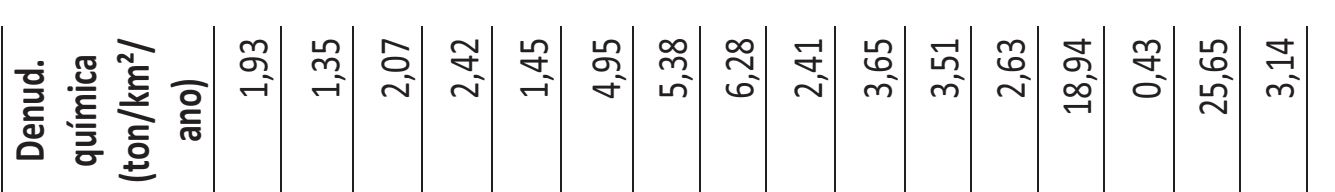



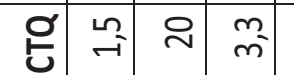

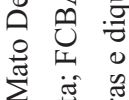

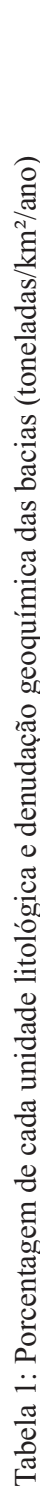

\begin{tabular}{|c|c|c|c|c|c|c|c|c|c|c|c|c|c|c|c|c|}
\hline & & & & & & & & & & & & & $\Rightarrow$ & & $m$ & \\
\hline & & ' & ' & ' & ' & & & T & & ' & ' & ' & $\sim$ & & 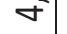 & ' \\
\hline 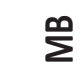 & $\stackrel{m}{m}$ & r & $m_{\infty}^{m}$ & $\stackrel{\infty}{\sim}$ & जi & $\stackrel{Q}{\sim}$ & ने & 명 & $\begin{array}{l}\stackrel{+}{ \pm} \\
\stackrel{J}{\mid}\end{array}$ & ò & \begin{tabular}{l}
$\mathscr{q}$ \\
\multirow{\sigma}{*}{}
\end{tabular} & $\tilde{m}$ & t) & & 宓 & $\tilde{w}^{-}$ \\
\hline
\end{tabular}

छ

\begin{tabular}{|c|c|c|c|c|c|c|c|}
\hline , & . & , & $\stackrel{\vec{m}}{\dot{m}}$ & 1 & , & , & 1 \\
\hline ' & ' & ' & ' & ' & ' & ' & ' \\
\hline & $\stackrel{\mathscr{L}^{m}}{m}$ & & & $\stackrel{\infty}{\sim}$ & & & \\
\hline
\end{tabular}

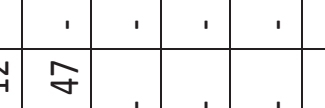

芯



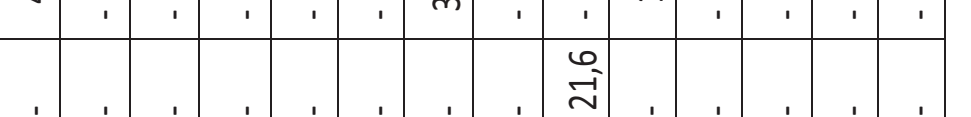

\begin{tabular}{|c|c|c|c|c|c|c|}
\hline & & & & & & \\
\hline & ' & ' & 1 & ' & ' & r্ \\
\hline & & & & & & ने \\
\hline
\end{tabular}

\begin{tabular}{|c|c|c|c|c|c|c|c|c|c|c|c|c|c|c|c|c|}
\hline $\begin{array}{l}\text { 訔 } \\
\text { 产 }\end{array}$ & I & , & , & $\exists$ & $\vec{\sim}$ & ' & & శ్ & 1 & ' & ' & ' & ' & ' & ' & ने \\
\hline a & & & & & & & $\ddot{N}$ & & & & & & & & & $\stackrel{\infty}{\sim}$ \\
\hline
\end{tabular}

$\stackrel{\text { s. }}{s}$

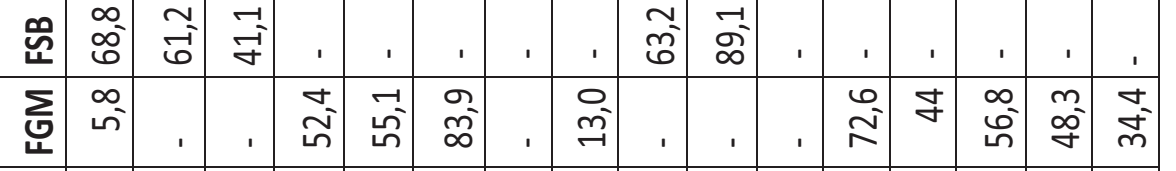


A influência litológica nas taxas de denudação geoquímica do médio Espinhaço Meridional - MG

Éric Andrade Rezende, Marina Ribeiro Leão, André Augusto Rodrigues Salgado, Carmélia Kerolly Ramos de Oliveira, Hermínio Arias Nalini Júnior

Tabela 2: TDS, vazão, área e denudação geoquímica das bacias estudadas - Verão

\begin{tabular}{|c|c|c|c|c|}
\hline \multirow[b]{2}{*}{ Bacia } & \multicolumn{4}{|c|}{ Estação úmida } \\
\hline & $\begin{array}{c}\text { TDS }(\mathrm{g} / \\
\left.\mathbf{m}^{3}\right)\end{array}$ & $\operatorname{Vazão}\left(\mathbf{m}^{3} / \mathbf{s}\right)$ & $\begin{array}{c}\text { Área } \\
\left(\mathbf{K m}^{2}\right)\end{array}$ & $\begin{array}{c}\text { Denudação Geoquímica } \\
\text { (ton/km²/semestre) }\end{array}$ \\
\hline Rio Jequitinhonha & 5,2755 & 7,98 & 390,62 & 1,70 \\
\hline Córrego Fundo (Moinho) & 3,8551 & 0,33 & 17,62 & 1,15 \\
\hline Rio Jequitinhonha (nascente) & 3,9804 & 0,18 & 20,67 & 0,56 \\
\hline Rio Parauninha & 4,8312 & 0,77 & 51,46 & 1,14 \\
\hline Rio Preto & 4,4062 & 0,43 & 28,80 & 1,04 \\
\hline Cór. Teodoro (Rabo de Cavalo) & 1,3028 & 3,52 & 16,68 & 4,33 \\
\hline Ribeirão Mata Cavalos & 4,5670 & 1,93 & 41,18 & 3,37 \\
\hline Rio Cuba (Três Barras) & 4,7068 & 5,47 & 75,42 & 5,39 \\
\hline Rio Paraúna & 4,4908 & 7,07 & 281,62 & 1,78 \\
\hline Córrego da Taquara & 5,9053 & 0,58 & 17,55 & 3,05 \\
\hline Córrego dos Fechados & 6,5332 & 0,70 & 29,67 & 2,42 \\
\hline Ribeirão da Areia & 6,0267 & 2,27 & 98,40 & 2,20 \\
\hline Córrego Lapinha & 13,6021 & 1,20 & 14,19 & 18,21 \\
\hline Córrego Lajeado & 2,9477 & 0,03 & 7,92 & 0,17 \\
\hline Córrego Mata-Capim & 5,2277 & 8,59 & 29,28 & 24,20 \\
\hline Ribeirão Capivara & 3,0245 & 3,90 & 66,43 & 2,80 \\
\hline
\end{tabular}

Tabela 3: TDS, vazão, área e denudação geoquímica das bacias estudadas - Inverno

\begin{tabular}{|c|c|c|c|c|}
\hline \multirow[b]{2}{*}{ Bacia } & \multicolumn{4}{|c|}{ Estação seca } \\
\hline & $\operatorname{TDS}\left(\mathrm{g} / \mathrm{m}^{3}\right)$ & $\operatorname{Vazão}\left(\mathbf{m}^{3} / \mathbf{s}\right)$ & $\begin{array}{c}\text { Área } \\
\left(\mathbf{K m}^{2}\right)\end{array}$ & $\begin{array}{l}\text { Denudação Geoquímica } \\
\text { (ton } / \mathrm{km}^{2} / \text { semestre) }\end{array}$ \\
\hline Rio Jequitinhonha & 6,7813 & 0,83 & 390,62 & 0,23 \\
\hline Córrego Fundo (Moinho) & 5,8672 & 0,04 & 17,62 & 0,19 \\
\hline Rio Jequitinhonha (nascente) & 6,3525 & 0,31 & 20,67 & 1,51 \\
\hline Rio Parauninha & 5,9234 & 0,70 & 51,46 & 1,28 \\
\hline Rio Preto & 6,0442 & 0,12 & 28,80 & 0,41 \\
\hline Cór. Teodoro (Rabo de Cavalo) & 4,9590 & 0,13 & 16,68 & 0,61 \\
\hline Ribeirão Mata Cavalos & 6,9262 & 0,76 & 41,18 & 2,02 \\
\hline Rio Cuba (Três Barras) & 6,4194 & 0,66 & 75,42 & 0,89 \\
\hline Rio Paraúna & 5,8935 & 1,92 & 281,62 & 0,63 \\
\hline Córrego da Taquara & 6,0069 & 0,11 & 17,55 & 0,59 \\
\hline Córrego dos Fechados & 15,7852 & 0,13 & 29,67 & 1,09 \\
\hline Ribeirão da Areia & 6,5058 & 0,42 & 98,40 & 0,44 \\
\hline Córrego Lapinha & 24,9897 & 0,03 & 14,19 & 0,73 \\
\hline Córrego Lajeado & 3,9635 & 0,03 & 7,92 & 0,26 \\
\hline Córrego Mata-Capim & 13,2744 & 0,20 & 29,28 & 1,44 \\
\hline Ribeirão Capivara & 4,3825 & 0,33 & 66,43 & 0,34 \\
\hline
\end{tabular}


predomínio dos quartzitos e também a outros fatores ambientais, como a vazão dos canais e o controle estrutural. Por esse motivo não é possível identificar claramente um padrão de influência dessas rochas nas taxas denudacionais. No entanto, com o apoio dos resultados obtidos por Salgado \& Valadão (2003) e Salgado et al. (2004) é possível inferir que as unidades onde prevalecem metapelitos são, em geral, menos resistentes que os quartzitos. Esse é o caso da Formação Córrego da Bandeira, que possui predomínio de metassiltitos e filitos (KNAUER et al., 1997) e está presente na bacia do Córrego dos Fechados. Já o comportamento dos xistos do Grupo Costa Sena se aproxima bastante das unidades quartzíticas, como pode ser verificado na bacia do Rio Jequitinhonha (nascente).

As mesmas observações referentes aos metapelitos são válidas para os granitos e gnaisses do Complexo Gouveia e para as intrusões de rochas metabásicas, essas últimas aparecem em quase todas as bacias, porém, ocupam sempre pequenas áreas. Por outro lado, as raras coberturas terciárias/quaternárias, mapeadas nas proximidades das nascentes do Rio Jequitinhonha, são arenosas e parcialmente lateritizadas (SOUZA, et al., 1997), o que indica que já foram intensamente lixiviadas e, hoje, possuem poucos elementos a serem transportados em solução, como pode ser observado na bacia do Córrego Fundo (Moinho).

A ocorrência desses processos de denudação geoquímica diferencial se manifesta na topografia, elaborada em conjunto com a erosão mecânica. Enquanto os quartzitos sustentam cristas e níveis planálticos elevados, as rochas carbonáticas e os metapelitos comumente ocupam depressões estreitas e alongadas que acompanham a direção geral da Serra do Espinhaço Meridional (NNW-SSE).

\section{CONSIDERAÇÕES FINAIS}

Os resultados obtidos deixam claro que a litologia é um dos principais fatores controladores das taxas de denudação geoquímica na área de estudo. A relativa homogeneidade litológica da porção meridional da Serra do Espinhaço não oculta a existência de uma denudação geoquímica diferencial, onde os quartzitos, notadamente as formações Galho do Miguel e Sopa-Brumadinho, apresentam maior resistência do que as demais litologias. Mesmo entre as próprias unidades predominantemente quartzíticas é possível identificar padrões de comportamento diferenciados frente aos processos químicos, como a maior fragilidade das Unidades Itambé do Mato Dentro e Rio Preto. Também merece destaque as elevadas taxas de perda geoquímica condicionadas pela presença de rochas carbonáticas.

Os dados aqui apresentados possibilitaram compreender mais claramente a influência do substrato geológico na quantidade de material dissolvido removido das bacias. No entanto, ficou evidente que analisando apenas este fator não é possível entender por completo as diferenças das taxas denudacionais entre as bacias. Neste contexto, torna-se necessário ampliar os estudos acerca da denudação geoquímica na Serra do Espinhaço Meridional.

\section{AGRADECIMENTOS}

Agradecemos à FAPEMIG, à CAPES e ao CNPQ pelo apoio financeiro que permitiu a realização deste trabalho.

\section{REFERÊNCIAS}

ALMEIDA-ABREU, P. A. O Supergrupo Espinhaço da Serra do Espinhaço Meridional (Minas Gerais): o Rifte, a Bacia e o Orógeno. Geonomos, Belo Horizonte, v. 3, n. 1, p. 1-18, 1995.

CHRISTOFOLETTI, A. Geomorfologia Fluvial. São Paulo: Edgard Blücher, v. 1, 1981.

DINIZ, et al. Relações Solos - Superfícies Geomórficas na Porção Norte da Bacia do Ribeirão Chiqueiro - Gouveia, MG. Geonomos, Belo Horizonte v. 13 $(1,2)$, p. 19-27. 2005.

GROSSI-SAD, J. H.; MOURÃO, M. A. A.; GUIMARÃES, M. L. V. \& KNAUER, L. G. Geologia da 
Folha Conceição do Mato Dentro. In: GROSSI-SAD, J. H.; LOBATO, L. M.; PEDROSA-SOARES, A. C. \& SOARES-FILHO, B. S. (Coord. e Ed.), Projeto Espinhaço em CD-ROM (textos, mapas e anexos). Belo Horizonte, COMIG - Companhia Mineradora de Minas Gerais. 1997. p. 2533-2693.

KNAUER, L. G. \& GROSSI-SAD, J. H. da. Geologia da Folha Presidente Kubitschek. In: GROSSISAD, J. H.; LOBATO, L. M.; PEDROSA-SOARES, A. C. \& SOARES-FILHO, B. S. (coordenadores e editores). Projeto Espinhaço em CD-ROM (textos, mapas e anexos). Belo Horizonte, COMIG - Companhia Mineradora de Minas Gerais. 1997. p. 1901-2055.

LEEDER, M. R. Denudation, Vertical Crustal Movements and Sedimentary Basin Infill. Geologische Rundschau. Stuttgart, v. 80, n. 2, p. 441-458, 1991.

MELO, M. S; CLAUDINO-SALES, V ; PEULVAST, J; SAADI, A ; MELLO, C. L. Processos e produtos morfogenéticos continentais. In: SOUZA, C. R. G.; SUGUIO, K.; OLIVEIRA, A. M. S.; OLIVEIRA, P. E. (Ed.) Quaternário do Brasil. Ribeirão Preto: Holos, 2005. p. 258-275.

NEVES, S. C.; ALMEIDA-ABREU, P. A.; FRAGA, L. M. S. Fisiografia. In: SILVA, A. C. et al. Serra do Espinhaço Meridional: Paisagens e Ambientes. Belo Horizonte: O Lutador, 2005. p. 47-58.

OLIVEIRA, M. J. R.; FOGAÇA, A. C. C. \& FONSECA, E. da. Geologia da Folha Baldim. In: GROSSI-SAD, J. H.; LOBATO, L. M.; PEDROSA-SOARES, A. C. \& SOARES-FILHO, B. S. (coordenadores e editores). Projeto Espinhaço em CD-ROM (textos, mapas e anexos). Belo Horizonte, COMIG - Companhia Mineradora de Minas Gerais. 1997. p. 2437-2531.
SAADI, A. A geomorfologia da Serra do Espinhaço em Minas Gerais e de suas margens. Geonomos, Belo Horizonte, v. 3, n. 1, p. 41-63, 1995.

SALGADO, A. A. R. Desnudação geoquímica e Evolução do Relevo no Espinhaço Meridional. 2002. 189p. Dissertação (Mestrado em Geografia) - IGC/ UFMG, Belo Horizonte, 2002.

SAlGADO, A. A. R.; VALADÃO, R. C. Contribuição da Desnudação Geoquímica para a Erosão diferencial no Espinhaço Meridional/MG. Revista Brasileira de Geomorfologia, Goiânia, v. 4, n. 2, p. 31-40, 2003.

SALGADO, A. A. R.; COLIN, F.; NALINI JR., H. A.; BRAUCHER, R.; VARAJÃO, A. F. D. C. \& VARAJÃO, C. A. C. O papel da denudação geoquímica no processo de erosão diferencial no Quadrilátero Ferrífero. Revista Brasileira de Geomorfologia, Goiânia, v. 5, n. 1, p. 55-69, 2004.

SILVA, A. C. et al. Serra do Espinhaço Meridional: Paisagens e Ambientes. Belo Horizonte: O Lutador, 2005.

SOUCH, C. Chemical denudation. In: GOUDIE, A. S. (Ed.): Encyclopedia of Geomorphology. London: Routledge, 2004. v. 1. p. 144-148.

SOUZA, M. A. T. A. \& GROSSI-SAD, J. H.. Geologia da Folha Rio Vermelho. In: GROSSI-SAD, J. H.; LOBATO, L. M.; PEDROSA-SOARES, A. C. \& SOARES-FILHO, B. S. (Coord. e Ed.). Projeto Espinhaço em CD-ROM (textos, mapas e anexos). Belo Horizonte, COMIG - Companhia Mineradora de Minas Gerais. 1997. p. 1667-1806.

SUMMERFIELD, M. A. Global Geomorphology: An introduction of the study of landforms. New York: Longman Scientific \& Technical, 1991. 
A influência litológica nas taxas de denudação geoquímica do médio Espinhaço Meridional - MG Éric Andrade Rezende, Marina Ribeiro Leão, André Augusto Rodrigues Salgado, Carmélia Kerolly Ramos de Oliveira, Hermínio Arias Nalini Júnior

VALADÃO, R. C. Evolução de longo termo do relevo do Brasil Oriental: desnudação, superficies de aplanamentos e soerguimentos crustais. 1998. 243p. Tese (Doutorado em Geologia) - Departamento de Geologia, Universidade Federal da Bahia, Salvador, 1998. 